\title{
Regression of Murine Ehrlich Ascites Carcinoma Using Tumor-Targeting Salmonella VNP20009 - Comparison with the Effect of the Anticancer Drug Doxorubicin
}

\author{
Alshaymaa A. El-Bahy ${ }^{1}$, Khaled Abou-Aisha ${ }^{2}$, Eman Noaman ${ }^{3}$ and Laila G. Mahran ${ }^{1}$ \\ ${ }^{1}$ Pharmacology and Toxicology Department, Faculty of Pharmacy and Biotechnology, GUC, Cairo, Egypt \\ ${ }^{2}$ Department of Microbiology and Immunology; Faculty of Pharmacy and Biotechnology, \\ GUC, Cairo, Egypt \\ ${ }^{3}$ National Center for Radiation Research and Technology (NCRRT), Cairo, Egypt
}

\begin{abstract}
The limited selectivity of therapeutic agents for tumor cells and their inability to act on poorly vascularized areas of tumors, remain among the primary limitations to cancer therapy. Several studies reported that Salmonella typhimurium VNP20009 (VNP) preferentially targets hypoxic/anoxic cores of solid tumors. Here the authors compare the antitumor effect of VNP with doxorubicin (Dox) and a combination of both agents, in a murine model of Ehrlich ascites carcinoma (EAC). Methods: Mice were randomly divided into four control groups and three treatment groups receiving VNP, Dox, or a combination of both. Plasma levels of the liver enzymes ALT and AST, and levels of urea and creatinine were measured colorimetrically; vascular endothelial growth factor (VEGF) was measured using ELISA and total free radicals were measured using electron spin resonance (ESR). Histopathological studies were performed on liver and tumor tissues. Apoptosis/necrosis and the tumor suppressor protein p53 levels were assayed by immunohistochemistry. Results: VNP treatment resulted in normal levels of ALT, AST, urea and creatinine. Less dense tumor cells with regeneration of skeletal muscle and almost normal architecture of liver tissues were observed in animals receiving VNP and combined therapy. Tumor volumes and VEGF levels were significantly lower in these two groups. Free radicals significantly increased in Dox-receiving group compared to the VNP and the combination group. Late stage apoptotic/necrotic cells were observed in tumor tissues treated with VNP, Dox or their combination, and p53 levels were higher in the same groups.

Conclusion: Monotherapy with VNP showed comparable antitumor effects to Dox, but seems to obviate the reported negative side-effects of Dox.
\end{abstract}

Key words: Salmonella typhimurium VNP20009, Doxorubicin, hypoxic/anoxic cores of solid tumors.

\section{Introduction}

Resistance to conventional anticancer therapies in patients with advanced solid tumors [Patyar et al., 2010]- in addition to the side effects that patients experience from conventional chemotherapy such as nausea, vomiting, hair loss and sometimes bone marrow suppression- have prompted the need of alternative cancer therapies. The aim of research in the cancer field is selectively targeting and destroying malignant cells and

Copyright (C) 2012 Müberra Yüksel. This is an open access article distributed under the Creative Commons Attribution License unported 3.0, which permits unrestricted use, distribution, and reproduction in any medium, provided that original work is properly cited. Contact author: Müberra Yüksel E-mail: muberray@khas.edu.tr 
preventing their spread. This goal has long remained elusive in large because of the extreme genetic and phenotypic variability of most tumors. There is, however, an important pathway that currently attracts interest, i.e., the restricted colonization of malignancies by facultative anaerobic bacteria [Yu et al., 2004]. Bacteria and bacterial products have been investigated as therapeutic agents to treat solid tumors for more than hundred years. In this aspect, several bacterial species have been discovered that can selectively accumulate and replicate in solid tumors. Lipid Amodified (msbB-), auxotrophic (purI-) $S$. typhimurium VNP20009 (VNP) is a genetically attenuated strain designed for tumor therapy [Low et al., 2004]. The deletion of above-mentioned virulence genes enhances the requirement for an external source of purine for bacterial replication and reduces the production of TNF-, thus eliminates the septic shock [Clairmont et al., 2000; Low et al., 2004]. Since hypoxia is a common characteristic of all tumors, which adversely affects the prognosis of cancer patients, targeting the hypoxic regions of tumors may increase the effectiveness of cancer treatment [Lee et al., 2005]. Thus, VNP is used in this study alone and in combination with doxorubicin (Dox; also called adriamycin) to combat solid tumor metastasis. VNP has several attractive properties for cancer treatment: First, it is highly sensitive to many commonly used antibiotics, and thus, infections can be managed. Second, S. typhimurium is a facultative anaerobe, (i.e., it can grow in aerobic and anaerobic conditions), it can selectively grow and preferentially replicate in tumor tissue, achieve tumor to normal tissue ratios in excess of 1,000 to 1 and result in reduced tumor growth [Pawelek et al., 1997]. Finally, it can be easily engineered in the laboratory to express foreign genes as well as to attenuate its pathogenicity [Rosenberg et al., 2002]. Several studies indicated the safe use of such a strain that does not induce septic shock during infection in animal models, and yet retains its tumortargeting capability. Jia et al. (2005) reported the use of $104 \mathrm{cfu}$ VNP with rhEndostatin and observed no significant toxicities, where the treated mice seemed as active as control mice and no obvious weight loss was observed.

Dox is one of the most frequently used anticancer drugs. It is used for the treatment of different hematopoietic and solid cancers, such as breast cancer, osteosarcomas, aggressive lymphomas and leukemias. It has the ability to intercalate between the DNA strands and hydrolyzes them in a nucleaselike manner [Fornari et al., 1994; Lentacker et al., 2010]. However, its use is limited due to its side effects, such as cardiotoxicity, nephrotoxicity and bone marrow suppression induced from high doses. Thus, the present work aims at comparing the antitumor effect of VNP alone, with its combination with a low dose of Dox in a murine model of Ehrlich ascites carcinoma, in mice.

\section{Materials and Methods:}

\section{Ethical Statement}

An initial number of 140 mice were used. All experimental procedures were carried out in accordance with the guide for care and use of laboratory animals published by the US National institute of Health [NIH publication, 1985].

All Experiments Have Been Conducted Under the Regulations and the Acceptance of the Ethics Committee of the German University in Cairo.

\section{Animals}

Because Ehrlich Ascites Carcinoma (EAC) cells were reported to show greater initial growth and total cell count in female than male mice [Vincent and Nicholls, 1967], the present study used female mice as experimental subjects. Two-Three weeks old female Swiss albino mice weighing 20-25 g were obtained from the Holding Company for Biological Products and Vaccines (VACSERA, 
Cairo, Egypt). Animals were housed 15-20 per cage, and allowed to become acclimatized to laboratory conditions for one week before the experiment. Animals were kept in a conditioned atmosphere at $25{ }^{\circ} \mathrm{C}$ and fed with standard laboratory pellets with tap water ad libitum.

\section{Tumor Cells Transplantation:}

A line of EAC cells was obtained from the Cancer Biology Department of the National Cancer Institute (Cairo, Egypt), and maintained by weekly intra-peritoneal transplantation of $2.5 \times 106$ cells / mouse. EAC cells were obtained from donor mice (Swiss albino) of 18-20 g body weight and suspended in sterile isotonic saline. A fixed number of viable cells (usually $2 \times 106$ cells/20 g body weight) were injected intramuscularly in the thigh of each recipient mouse [Gothoskar and Ranadive, 1971]. The viability of the cells was $99 \%$ as judged by trypan blue exclusion assay.

\section{Salmonella Strain and Bacterial Infection:}

The VNP salmonella strain ( $m s b \mathrm{~B}-$ and purI-; a kind gift from Prof. B. low; Yale University) was cultured and prepared as described by Low et al., [2004]. Briefly, VNP strain was grown in modified Luria-Bertani (LB) broth without sodium chloride to late log phase (OD600 = 0.9). Bacteria were harvested by centrifugation at 6000 ' $\mathrm{g}$ for $20 \mathrm{~min}$, and cell pellets were re-suspended in PBS $(\mathrm{pH}=7.4)$. Bacteria were administered intramuscularly in three equal injections (each containing $2 \times$ $104 \mathrm{CFU}$ ) to mice over a period of one week and three equal injections (each containing $2 \times 105 \mathrm{CFU}$ ) to mice over a period of another week. All mice were treated with bacteria for two weeks after bearing approximately 9 days-old solid EAC.

\section{Drug Preparation:}

Dox was purchased in the form of a solution from Bedford Laboratories (England) and adjusted to the required concentration (see below) by the addition of sterile $0.9 \%$ saline and used immediately. The appropriate working solutions were prepared in a total volume of one $\mathrm{ml}$ that contained the required dose per Kg body weight. Mice received Dox intramuscularly (i.m.) in three equal injections each containing $5 \mathrm{mg} / \mathrm{kg}$, over a period of one week and three equal injections (each containing $10 \mathrm{mg} / \mathrm{kg}$ ) over a period of another week. All mice were treated with doxorubicin for two weeks after bearing approximately 9 days old solid EAC.

\section{Experimental Design}

Mice were randomly divided into seven 20 mice groups (a total of 140 female mice, 2-3 weeks old, 20-25g weight). In Group I (Gp I; control group), animals received no treatment. Gp II (Tumor group): animals were inoculated in the back between the thighs with EAC cells. Each mouse was injected, once, subcutaneously with $2.5 \times 106$ $\mathrm{EAC} / \mathrm{ml}$ to induce the formation solid tumors [Fahim et al., 1997]. Gp III (designated hereafter as VNP group): mice received injections with a suspension of VNP cells at densities of $2 \times 104$ colony forming units ( $\mathrm{cfu}$ ) every other day for one week and $2 \times 105 \mathrm{cfu}$ every other day for another week. Gp IV (Dox group): mice were injected with Dox at doses of $5 \mathrm{mg} / \mathrm{kg}$ every other day for a week and then $10 \mathrm{mg} / \mathrm{kg}$ every other day for another week. Gp V (VNP-Tumor group): mice bearing EAC treated with VNP at the same doses of Gp III. Gp VI (Dox, Tumor): mice bearing EAC treated with Dox at the same doses of Gp IV. Gp VII (VNP, Dox, Tumor group): mice bearing (EAC) received a combination of both treatments: VNP at doses of 2'105 cfu in three-dose injections over one week, and Dox at a $5 \mathrm{mg} / \mathrm{kg}$ dose every other day for another week. An eighth group of normal (non-tumor-bearing) animals that received both the indicated doses of VNP and Dox, was also investigated; however, the safety profile of these animals was identical with that of the Dox treated group (not shown) and therefore were excluded from the study in order to reduce the cost of the downstream analyses (ESR, p53,...etc). 


\section{Blood Sampling}

After 31 days from the outset of the experiment, animals were anesthetized using diethyl ether, blood samples were collected from the heart using heparinized syringes, transferred to heparinized tubes and then centrifuged at 2000 ' $\mathrm{g}$ for 15 minutes. The plasma was collected and stored at $-20^{\circ} \mathrm{C}$ for less than a week until being analyzed for urea and creatinine as indicators of kidney function, and for aspartate aminotransferase (AST) and alanine aminotransferase (ALT) as indicators of liver function.

\section{Tissue Sampling}

After 31 days from the outset of the experiment, animals were sacrificed and tissue portions from the tumor and liver were prepared for sectioning and kept in $10 \%$ formalin for histopathological examination and for detection of apoptotic or necrotic tissues and p53 levels.

\section{Measurement of Tumor Growth and Evaluation of Toxicity}

\section{Body Weight and Tumor Weight}

Animals were weighed on every other day throughout the period of the experiment, and the weight of tumor-bearing mice weight was determined by subtracting the tumor weight (after sacrificing the animal) from animal weight.

\section{Tumor Volume}

Antitumor effects of the different treatments were evaluated by tumor growth inhibition. Tumors were measured individually using a caliper. Tumor volume was determined by the following formula:

Tumor Volume $=$ length $\times$ width $2 \times 0.52$ [ia et al., 2005].

\section{Determination of Liver and Kidney Functions}

Both plasma alanine aminotransferase and aspartate aminotransferase (ALT and AST) and plasma urea and creatinine were determined colorimetrically using test reagent kits (Mediserve Company; Egypt for liver enzymes and Randox; UK for kidney functions), according to the manufacturer's instructions.

\section{Plasma VEGF Assay}

Plasma VEGF was assessed colorimetrically using an enzyme-linked immunosorbent assay (ELISA) kit (Ray Bio Inc., USA). The plasma used was diluted 1 to $2 \times$ before performing the analysis, according to the manufacturer's instructions.

\section{ESR-Determination of Total Free Radicals}

Total free radicals in the red blood cells (RBCs) of mice were measured by ESR according to the method of Heckly [1972 and 1976]. RBCs were first lyophilized (Edwards, Piran 501, Freeze dryer super Modulyo, England) before use. ESR signals were recorded at room temperature by using a Bruker EMX spectrometer (X-Band) (Bruker, Germany). The operating conditions were as follows: microwave power, 5.053 $\mathrm{mW}$; modulation amplitude, $6.00 \mathrm{G}$; modulation frequency, $100.00 \mathrm{kHz}$; sweep width, $120.000 \mathrm{G}$; microwave frequency, $9.700 \mathrm{GHz}$; time constant, $81.920 \mathrm{~ms}$; sweep time, 20.972 s. The detection limits of ESR technique depend on the type of sample, sample size, detector sensitivity, frequency of the incident radiation and the electronic circuits of the instrument. 


\section{Analysis of ESR Data:}

For monitoring variations in the peak height EPR signals as a function of magnetic field, intensities were measured as the distance between top and bottom points of the first derivative recorded according to Gohn, [1986]. Quantitative assessments of free radical concentration were made by the following equation:

$\mathrm{Nd}=\mathrm{K} .[\mathrm{HO}(\Delta \mathrm{H}) 2 \mathrm{~A} / 2] /[\mathrm{HmGe} \sqrt{\mathrm{PH}}]$

Where: Nd: number of radicals, K: factor depending on the experimental condition of the spectrophotometer $=1013 / \mathrm{cm}, \mathrm{HO}$ : Magnetic field at peak center in gauss, ${ }^{\Delta} \mathrm{H}$ : Width peak to peak, A: peak height/weight, $\mathrm{Hm}$ : modulation field, $\mathrm{PH}$ : power in $\mathrm{mW}=$ $5.053 \mathrm{~mW}$,

Ge: gain of the detector $=1 \mathrm{x}$ 104, Concentration $=$ unpaired electrons - or spin per sample weight in grams.

\section{Immunohistochemistry}

The apoptosis and necrosis staining were analyzed using the method of Ribble et al., [2005]. Briefly, 2-4 $\mu \mathrm{m}$ thick tissue sections were cut from paraffin embedded blocks by microtome and mounted from $40^{\circ} \mathrm{C}$-warm water onto charged adhesive slides. Sections were allowed to dry overnight at room temperature. Paraffin was removed by immersing slides in 3 changes of xylene for 5 min each, followed by washing in two changes graded alcohol for $3 \mathrm{~min}$ each as follows $100 \%, 95 \%, 80 \%$ and $50 \%$. Then, they were rinsed in 3 changes of PBS. A mixture of $100 \mu \mathrm{g} / \mathrm{ml}$ acridine orange and $100 \mu \mathrm{g} / \mathrm{ml}$ ethidium bromide was prepared in PBS. The slides were soaked in that mixture for 20 minutes before washing in PBS. The tissue uptake of the stain was monitored under a fluorescence microscope (Carl Zeis 37082, Germany with filter set 15), and the apoptotic, necrotic and viable regions were scored according to Sannino and Shousha [1994]. p53 was assayed using Invitrogen's HISTOSTAIN $®$ BULK kit, USA. The kit stains tissues using the Labeled-Streptavidin-Biotin (LAB-SA) method of Elias et al.,[1989],also known as Streptavidin-Biotin Amplification. The design employs Horse Radish Peroxidase (HRP) streptavidin, and a two-tiered antibody technique to reveal the presence of antigens in a variety of human tissues and cell preparations. After a user-supplied primary antibody has been bound to a target antigen, the LAB-SA method uses an affinitypurified and biotinylated secondary antibody, which binds specifically to that primary antibody. HRP labeled streptavidin is then bound to this biotinylated secondary antibody and the entire complex is revealed by adding a substrate/chromogen mixture, which creates an intense color deposit through the activity of the bound enzyme.

\section{Histopathological Estimation of Tumor}

Portions of the formalin-fixed tumor were embedded in paraffin, sectioned and stained with hematoxylin and eosin stain (H\& E) for histopathological examination under a light microscope (Banchroft et al., 1996).

\section{Statistical Analysis}

Results were expressed as means \pm standard deviation. Comparisons between different groups were carried out by one-way analysis of variance (ANOVA) followed by TukeyKramer multiple comparison test (Armitage and Berry, 1987) using GraphPad Prism (version 5) software.

\section{Results}

a. Liver- and Kidney-Function Tests:

Tumor-Free Groups: Compared to the respective control, administration of VNP resulted in normal values of ALT and AST ( $p>0.05$ ) and significant 24\% decrease in the urea levels and no significant difference in the creatinine levels. 
On the other hand, injection with Dox showed significant increase in the ALT levels by $96 \%, 88 \%$ and the AST levels by $30 \%$, $24 \%$, respectively, relative to the control and bacteria groups $(\mathrm{p}<0.05)$. The same treatment resulted in significant elevation in the urea levels by $32.23 \%$ and $73.17 \%$ and in the creatinine levels by $10 \%, 15 \%$, respectively.

Tumor-Bearing Groups: The treatment with VNP showed significant reduction in the ALT levels by $30 \%, 31 \%$ and the AST levels by $15 \%, 17 \%$, respectively, as compared to the tumor and Dox groups. The combination group showed significant reduction in the ALT levels by $5 \%$ and the AST levels by $13 \%$ as compared to the tumor group, and significant increase in the ALT levels by $37 \%$ as compared to the bacteria group. No significant difference was observed between the tumor and the Dox groups in both parameters (Table 1).

No Significant difference in creatinine levels was observed between all treatment groups ( $>0.05)$. However, VNP showed significant $18 \%$ decrease in urea levels as compared to the tumor group. No significant difference in urea levels is seen between the VNP- and the combination groups. Administration of Dox resulted in significant, almost two-fold increase, in urea levels as compared to the tumor, bacteria and combination groups by $85 \%, 127 \%$ and $98 \%$, respectively (Table 1 ).

Table 1. Effect of Bacteria, Doxorubicin and Combination of Both on Liver Enzymes and Kidney Function Tests in Tumor Bearing and Tumor Free Mice (Mean $\pm S E, N=20$ )

\begin{tabular}{|l|l|l|l|l|}
\hline & ALT & AST & urea & creatinine \\
Parameters & (U/L) & (U/L) & (mg/dl) & (dl) \\
\hline Gp I & 60.25 & 16.32 & 41.45 & 1.613 \\
& \pm & \pm & \pm & \pm \\
& 1.26 & 1.03 & 0.34 & 0.06 \\
\hline Gp II & $133 \#$ & $25.42 \#$ & 39.91 & 1.548 \\
& \pm & \pm & \pm & \pm \\
& 0.82 & 1.13 & 5.36 & 0.05 \\
\hline Gp III & 62.75 & 17.08 & $31.65 \#$ & 1.536 \\
& \pm & \pm & \pm & \pm \\
& 1.71 & 0.86 & 2.13 & 0.05 \\
\hline Gp IV & $118 \# * *$ & $21.24 \# * *$ & $54.81 \# * *$ & $1.77 \# * *$ \\
& \pm & \pm & \pm & \pm \\
& 0.82 & 1.54 & 0.26 & 0.10 \\
\hline Gp V & $92.5 \#$ @ & $21.7 \#$ @ & $32.64 \#$ @ & 1.708 \\
& \pm & \pm & \pm & \pm \\
& 1.29 & 1.10 & 2.66 & 0.13 \\
\hline Gp VI & $134 \# \$$ & $26.1 \#$ \$ & $74.02 \#$ @ \$ & 1.841 \\
& \pm & \pm & \pm & \pm \\
& 1.826 & 1.134 & 0.1986 & 0.1125 \\
\hline Gp VII & $127 \# @ \$ *$ & $22.14 \#$ @ $*$ & $37.44 *$ & 1.601 \\
& \pm & \pm & \pm & \pm \\
& 0.82 & 1.15 & 0.26 & 0.17 \\
\hline
\end{tabular}

$\# p<0.05$ vs. Control, @ $p<0.05$ vs. Tumor, $\$ p<0.05$ vs. VNP,Tumor, ${ }^{*} p<0.05$ vs. Dox,Tumor, ${ }^{* *} p<0.05$ vs. VNP 


\section{a. Body Weight:}

Tumor-Free Groups: Injection with bacteria did not result in weight loss of animals, while administration of Dox showed a $17 \%$ and $18 \%$ weight losses compared to the control and the VNP groups $(\mathrm{p}<0.05)$, respectively, probably indicating that this drug was used at its maximum tolerated dose.

Tumor Bearing Groups: A slight (9\%) but significant weight loss was observed upon administration of Dox in comparison with the tumor, VNP and combination thereof, and no significant weight change was observed between the tumor, VNP and combination groups ( $p>0.05)$ (data not shown).

\section{b. Tumor Weight and Volume:}

Compared to the tumor and Dox groups, VNP injections resulted in significant reductions in tumor weight by $83 \%, 55 \%$ and tumor volume by $95 \%$ and $91 \%$, respectively. Similar results were obtained when both a combination of both Dox and VNP were applied. This effect was less pronounced in the Dox group which showed reductions in tumor weight by $55 \%$ and tumor volume by $49 \%$ as compared to the tumor group. No significant difference is observed between the VNP and the combination groups in both parameters (Figure1a, 1b).

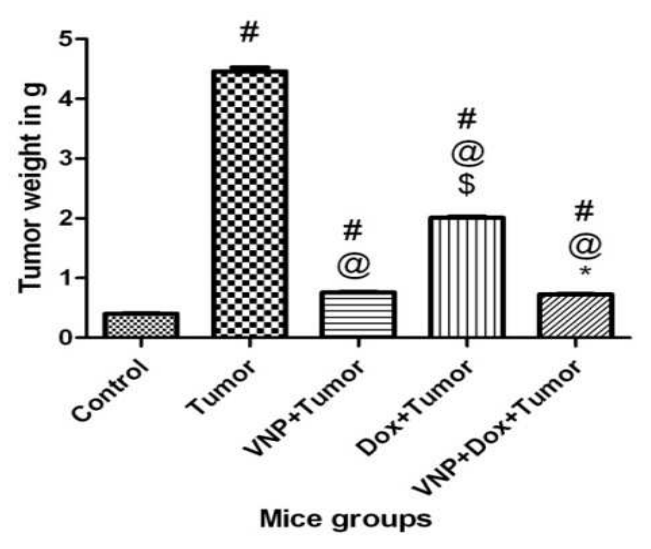

Fig. (1a)

Effect of VNP, Dox and Combination of Both on Tumor Weight

Each bar with vertical line represents the mean of 20 experiments \pm SD of the mean.

\#: Significantly different from the control group at $\mathrm{p}<0.05$.
@: Significantly different from the tumor group at $\mathrm{p}<0.05$.

\$: Significantly different from the VNP+tumor group at $\mathrm{p}<0.05$.

*: Significantly different from the Dox+tumor group at $\mathrm{p}<0.05$. 


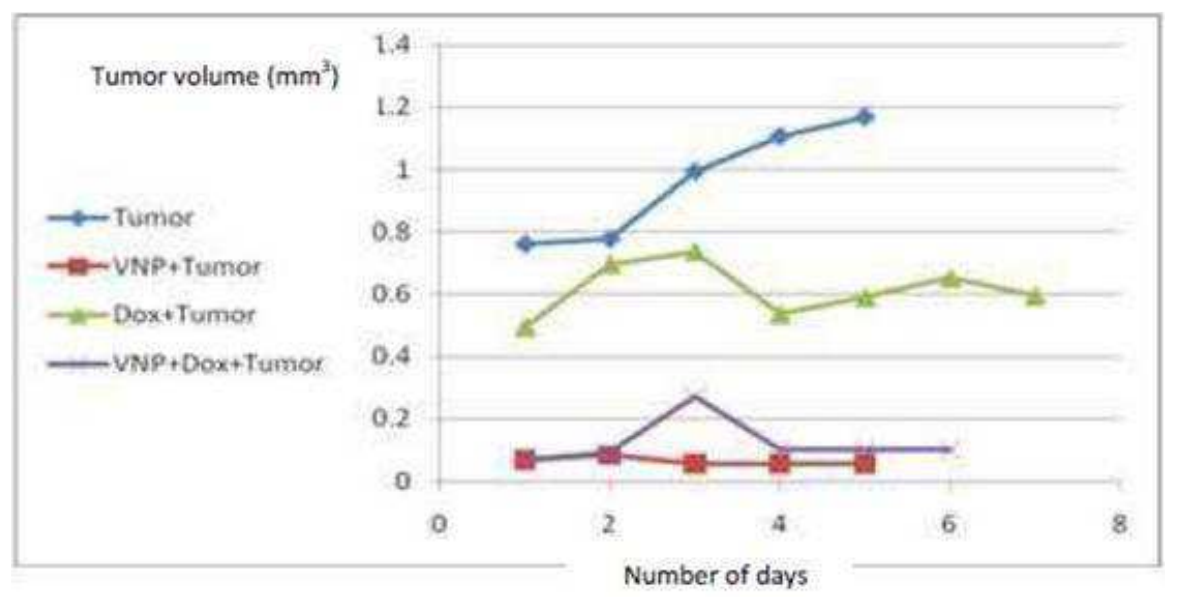

Fig. (1b) Effect of Bacteria, Doxorubicin and Combination of Both on Tumor Volume

Effect of Bacteria, Doxorubicin and Combination of Both on Tumor Volume

\section{c. Total Free Radicals:}

Tumor Free Groups: Both VNP- and Doxtreated animals produced significantly higher levels of total free radicals of RBCs, as compared to the control animals. The total free radicals were highest; however, in Dox- treated animals, almost two-fold higher than the control.

Tumor Bearing Groups: VNP showed no significant difference in their RBCs free radical count between the tumor and the combination groups. On the other hand, treatment with Dox resulted in significant elevation in the total free radicals of RBCs compared to the tumor, VNP and the combination groups by $85.93 \%, 55.37 \%$ and $54.52 \%$ respectively (Fig. 2 ).

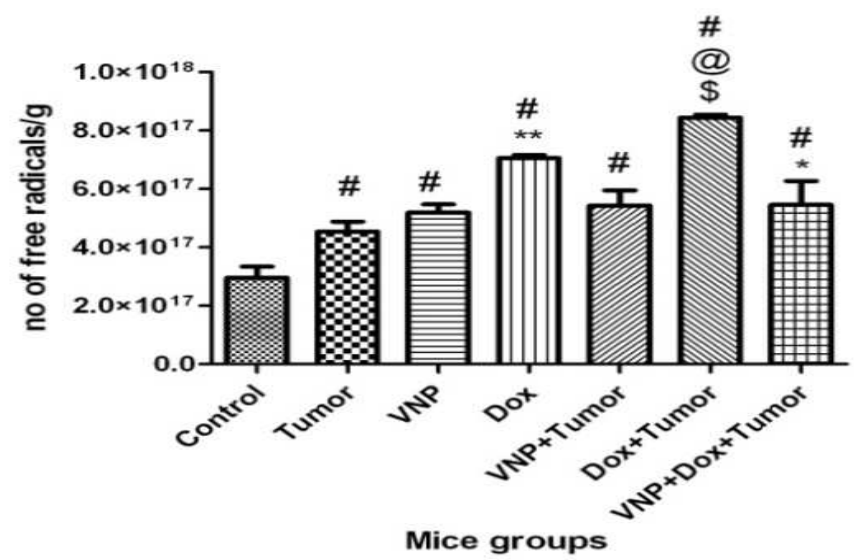

Fig. (2) 
Effect of Bacteria, Doxorubicin and Combination of Both on Total Free Radicals in Rbcs of Mice

**: Significantly different from the VNP group at $\mathrm{p}<0.05$.

\section{d. Vascular Endothelial Growth Factor (VEGF):}

Tumor Bearing Groups: The bacteria and combination groups resulted in significant reduction in the VEGF levels by $28 \%$ and $35 \%$ as compared to the control group, and by $58 \%$ and $62 \%$, respectively, as compared to the tumor group. No significant difference $(p>0.05)$ was observed between the Dox and the bacteria groups, while Dox showed significant reduction by $50 \%$ as compared to tumor group. In addition, the combination group showed significant reduction in the VEGF levels compared to the Dox group by $24 \%$ and no significant difference compared to the bacteria group (Fig. 3).

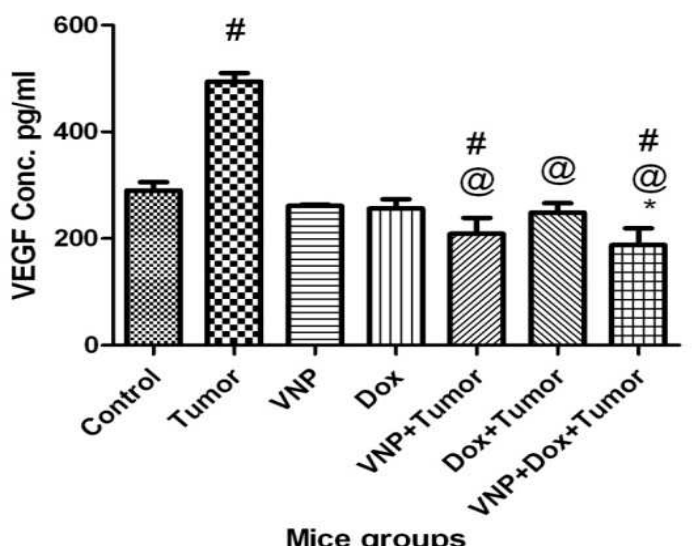

Fig. (3)

Effect of Bacteria, Doxorubicin and Combination of Both on VEGF Levels in Rbcs of Mice

\section{e. Apoptosis/Necrosis:}

The histochemical examination of apoptosis/necrosis in tumor tissue of Ehrlich carcinoma bearing mice under different conditions is shown in Figure (4), where the treatment with bacteria showed sporadic late stage apoptotic/necrotic cells with average score $(+)$, the treatment with Dox showed more late stage apoptotic /necrotic cells with average score (++) and the combination of both treatments showed nearly $90 \%$ late stage apoptotic/necrotic cells with average score $(+++)$. 


\begin{tabular}{|l|l|}
\hline Tumor group & VNP group \\
\hline & \\
\hline Doxorubicin group & Combination group \\
\hline & \\
\hline $\begin{array}{l}\text { Healthy cells are permeable to AO stain and impermeable to EB } \\
\text { stain, AO binds to the DNA and fluoresce green, while dead cells } \\
\text { are permeable to both stains which bind to the DNA and the EB } \\
\text { produces a strong signal which fluoresce orange. }\end{array}$ \\
\hline
\end{tabular}

Fig. (4): Histochemical Examination of Apoptosis/Necrosis in Tumor Tissue of Ehrlich Carcinoma Bearing Mice under Different Treatments.

\section{f. P53 Levels:}

The histochemical examination of p53 levels in tumor tissue of Ehrlich carcinoma bearing mice under different conditions is shown in
Figure (5), where the tumor untreated groups showed absence of p53 and the treatment with bacteria, Dox and the combination showed enhanced levels of p53. 


\begin{tabular}{|l|c|}
\hline Tumor group & VNP group \\
\hline & Combination group \\
\hline Doxorubicin group & \\
\hline & \\
\hline & \\
The slides were stained with Hematoxylin and Eosin which stains the \\
cell nuclei blue and with horse raddish peroxidase conjugated \\
antibodies which produce brown color for p53 expression.
\end{tabular}

Fig.(5) The Histochemical Examination of P53 Expression in Tumor Tissue of Ehrlich Carcinoma Bearing Mice under Different Conditions.

\section{g. Histopathological Estimation:}

\begin{tabular}{|c|c|c|}
\hline Control group & VNP group & Doxorubicin group \\
\hline 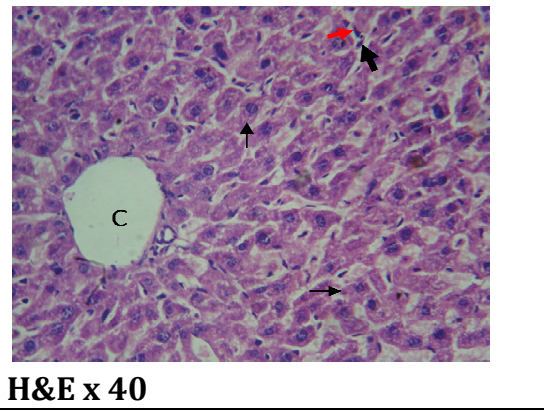 & 3 & a \\
\hline $\begin{array}{l}\text { Liver of control mouse showing } \\
\text { normal architecture of hepatocytes } \\
\text { radiating chord from central vein } \\
\text { (c). Acidophylic hepatocytes with } \\
\text { central vesicular tweleus ( ), } \\
\text { narrow blood sinusoids with } \\
\text { endothelial } \rightarrow \text { and kupffer cells ( } \\
\text { ). }\end{array}$ & $\begin{array}{l}\text { Liver of control mouse treated } \\
\text { with VNP showing normal; } \\
\text { hepatocytes }(\mathrm{H})(\text { as } \\
\text { central vein (V) and blood } \\
\text { sinusoids (BS). }\end{array}$ & $\begin{array}{l}\text { Liver of control mouse treated } \\
\text { with doxorubicin showing } \\
\text { degeneration of hepatocytes with } \\
\text { Karyolysis of their nuclei ( ) and } \\
\text { dilated central vein with } \\
\text { heamorage }(\mathrm{H}) \text {. Dilated blood } \\
\text { sinusoids ( ) and Monocytes } \\
\text { infiltration were seen ( ). }\end{array}$ \\
\hline
\end{tabular}

Fig. (6) The Histopathological Estimation of Liver Cells in Tumor Free Mice 


\begin{tabular}{|c|c|c|c|}
\hline Tumor group & VNP+Tumor group & Dox+Tumor group & Combination group \\
\hline H\&E X40 & H\&E X40 & H\&E X40 & H\&E X40 \\
\hline $\begin{array}{l}\text { Liver of tumor-bearing } \\
\text { mouse shows dilated blood } \\
\text { sinusoids pressing and } \\
\text { shifting on hepatocytes }(- \text { ). } \\
\text { In addition, Mitosis of } \\
\text { some hepatocytes i seen ( } \\
\text { ). }\end{array}$ & $\begin{array}{l}\text { Liver of tumor-bearing } \\
\text { mouse treated with VNP } \\
\text { showing mostly normal } \\
\text { hepatocytes with normal } \\
\text { Nucleus } \leftrightarrow \text { ) and narrow } \\
\text { blood sinusoids ( } \rightarrow \text { ), } \\
\text { normal central vein (v). } \\
\text { Partial protection is seen } \\
\text { upon treatment with } \\
\text { bacteria. }\end{array}$ & $\begin{array}{l}\text { Liver of tumor-bearing } \\
\text { mouse treated with } \\
\text { doxorubicin shows } \\
\text { infiltration of monocytes } \\
\text { (inflammation) } \\
\text { around the dilated central } \\
\text { vein }(\mathrm{C}) \text {, dilated sinusoids } \\
(\mathrm{)})\end{array}$ & $\begin{array}{l}\text { Liver of tumor-bearing } \\
\text { mouse treated with } \\
\text { combination therapy } \\
\text { shows relatively normal } \\
\text { hepatocytes }(\rightarrow) \text { ) and } \\
\text { infiltration of monocytes } \\
(\rightarrow) \text { around the central } \\
\text { vein is also seen (C). }\end{array}$ \\
\hline
\end{tabular}

Fig. (7) The Histopathological Estimation of Liver Cells in Tumor Bearing Mice

\begin{tabular}{|c|c|c|c|}
\hline Tumor group & VNP+Tumor group & Dox+Tumor group & Combination group \\
\hline H\&E X10 & H\&E X10 & H\&E X10 & H\&E X10 \\
\hline $\begin{array}{l}\text { Tumor tissue of mouse } \\
\text { bearing (EAC) } \\
\text { showing masses of } \\
\text { tumor cells }(\text { ). }\end{array}$ & $\begin{array}{l}\text { Tumor tissue of } \\
\text { (EAC) bearing } \\
\text { mouse treated with } \\
\text { VNP showing small } \\
\text { area of tumor cell ( } \\
\text { ) which contains } \\
\text { some hemorrhage } \\
\text { (H). }\end{array}$ & $\begin{array}{l}\text { Tumor tissue of (EAC) } \\
\text { bearing mouse treated } \\
\text { with doxorubicin } \\
\text { showing relatively } \\
\text { dense tumor cells } \\
\text { pressing on } \rightarrow \text { the } \\
\text { muscle tissue ( ). } \\
\text { Rupture of the } \\
\text { muscular tissue in the } \\
\text { right side of photo is } \\
\text { also seen ( ). }\end{array}$ & $\begin{array}{l}\text { Tumor tissue of } \\
\text { (EAC) bearing mouse } \\
\text { treated with } \\
\text { combination therapy } \\
\text { showing relative } \\
\text { decrease in tumor } \\
\text { cells. }\end{array}$ \\
\hline
\end{tabular}

Fig. (8) The Histopathological Estimation of Tumor Tissue in Mice 


\section{Discussion}

Two major limitations are known to negatively affect the utilization of anticancer agents for therapy. First, the lack of selectivity for tumor cells, and second, the cytotoxicity of these chemical substances, especially when applied in high doses. Since hypoxic conditions (or anoxia) prevail inside solid tumor tissues, several anaerobic bacterial strains, such as Bifidobacterium longum (Yazawa et al., 2000), and Clostridium novyi (Dang et al., 2001) or the facultative anaerobe Salmonella typhimurium [Low et al., 1999], preferentially target and accumulate in solid tumors by exploiting the conditions of impaired circulation and extensive necrosis of these malignant growths.

The hypoxic areas of tumors are poorly vascularized and are not likely to be treated easily with conventional chemo- and radiotherapeutics [Brown and Giaccia, 1998]. Since hypoxia is a common characteristic of human tumors, which adversely affects the prognosis of cancer patients, targeting the hypoxic regions of tumors is believed to increase the effectiveness of cancer therapy (Lee et $\boldsymbol{a l}$., 2005).

This study was originally initiated to investigate the effects of combinatorial treatment utilizing a conventional, low-cost anticancer drug, doxorubicin, in presence of the tumor-targeting bacterial strain VNP. Monitoring body weight, liver-, kidneyfunction tests and histopathological studies have been used to assess the toxicity of the applied doses of doxorubicin and/or VNP over a 31day experimental period. The present results confirm earlier data obtained by other groups reporting significant reductions in both tumor volumes (Fig. 1a, 1b) and weight compared to their respective controls (Jia et al., 2005; Jia et al., 2007).

The kidney is continuously exposed to different drugs and/or metabolites, which could cause the accumulation of nephrotoxins (Weinberg et al., 1996). The creatinine and urea blood tests were used in the present study to assess the kidney functions. Taken together, the present data indicates a significant increase in the levels of both parameters in animal which received high doses of Dox and significantly decreased when VNP was administered alone. This trend might be explained by potential nephrotoxicity known to accompany the administration of chemotherapeutics. Shinde et al. (2010) found that a single dose of Dox $15 \mathrm{mg} / \mathrm{kg}$ induced nephrotoxicity by significantly increasing both serum urea and creatinine. However, the exact mechanism by which the bacteria exert its protective effect on the kidney functions is still unclear. These findings suggest that bacterial treatment provides a safer toxicity profile than Dox as a representative chemotherapeutic agent.

A similar trend was observed when the hepatic markers ALT and AST levels were monitored. The elevation in liver enzymes of mice treated with Dox has already been reported in early studies (and is still consistent with more recent results (Sakr et al., 2010). Dox is now known to be extensively metabolized in the liver, generates ROS and produces lipid peroxidation, which could damage plasma membranes (Wallace, 2007). One important result of the present study is the lack of hepatic toxicity signs upon treatment with bacteria, a result that was further supported by histopathological examinations performed on the liver.

The results show significant reductions in both tumor weights and volumes of animals treated with bacteria and / or Dox with maximum reductions attained under combinatorial treatment (Gp VII) regime, which resulted in an almost complete disappearance of the tumor $(90 \%$ of original volume). These results are in accordance with other studies that proved the antimetastasis effect of the same strain of Salmonella. Rosenberg et al. (2002) proved that administration of VNP at dose 106 slowed the growth of the tumor. Melanomas 
in mice treated with Salmonella msbB mutant were $6 \%$ the size of tumors in untreated controls (Low et al., 1999). In addition, Jia et al. (2005) combined $104 \mathrm{cfu}$ VNP with rh-Endostatin and significant tumor growth inhibition was observed.

Most experimental solid tumors have elevated levels of ROS (Maeda and Akaike, 1998). Thus, in the present study a significant expected elevation of free radicals in the tumor group was observed. It has been suggested that infection with VNP may stimulate the production of ROS generating cells, such as activated macrophages and $\mathrm{T}$ lymphocytes (Avogadri et al., 2008). Nevertheless, the level of ROS generated by VNP treatment was $50 \%$ lower than that generated by Dox, suggesting a higher safety profile of VNP either alone or in combination with low doses of Dox: (5 mg/ $\mathrm{kg}$ ) versus using Dox at high doses $(5 \mathrm{mg} / \mathrm{kg}$ plus10 $\mathrm{mg} / \mathrm{kg}$ ) alone.

Tumor angiogenesis is a critical component of tumor growth and metastasis (Sheela et al., 2008). Thus, targeting the vascular supply of tumors is an intense field of interest in cancer therapy (Veikkola and Alitalo, 2004). Vascular endothelial growth factor (VEGF) is one of the most important angiogenic factors associated closely with the induction and maintenance of neovasculature in tumors (McMahon, 2000). Therefore, the inhibition of VEGF expression in tumor cells is a known strategy that impacts the angiogenesis-dependent tumor growth and metastasis. In accordance with several studies, increased levels of VEGF levels were measured in Ehrlich Ascites Tumors (Ghosh et al., 2004; Hassan and Abdel-Gawad, 2010). Injecting mice bearing EAC with $104 \mathrm{cfu}$ of VNP (Gp. V) resulted in significant reduction in the VEGF levels, as compared to the untreated group bearing EAC (Gp. II) and the control group (Gp. I). Taken together, the present results suggest that VNP can be employed as a potent antiangiogenic agent in agreement with other findings (Jia et al., 2005; Weinberg et al., 1996). It is suggested that VNP probably induce tissue necrosis formation in these tumors (Jia et al., 2005; Jia et al., 2007b) and the fact that many cytokines produced in host defense against Salmonella, such as IL12 and IL-18, IFN-g, could inhibit angiogenesis suggests that the decrease in VEGF observed in this study might partly result from the influence of bacteria on tumor angiogenesis (Cao et al., 2007). Treatment of mice bearing EAC with Dox (Gp. VI) showed significant reduction in the VEGF levels as compared to the untreated tumor bearing mice (Gp. II), while no significant difference appeared when compared to Gp. I (control). These results are consistent with Duyndam et al. (2007) who demonstrated that Dox abolishes hypoxia-induced VEGF mRNA expression in ovarian cancer cell lines, while basal VEGF mRNA expression was also down-regulated. Zhou (2005) stated that combining bacteriolytic therapy with angiogenesis inhibitors holds a unique position. The authors show that a combination of VNP and Dox in EAC-bearing mice (Gp VII) have led to a significant reduction in the VEGF production than using doxorubicin alone (Gp IV; dox only) and Gp VI (Dox + tumor). Moreover, the combination have led to a more profound inhibition of VEGF production in comparison to the control group (Gp I) and the untreated tumor-bearing group (Gp II). Also significant reduction was seen upon comparing the combination group with the group that received VNP control group (Gp III). Again, these data are in agreement with Jia et al. (2007) who reported a significant inhibition in tumor angiogenesis and VEGF production upon using a combination of bacteria with cyclophosphamide (Weinberg et al., 1996). Targeting the hypoxic regions of the tumor by the bacteria probably makes these regions more accessible to the chemotherapeutic agent resulting in the observed synergistic effect of the combination therapy on inhibiting VEGF production (Jain, 2000; Yu et al., 2004). The combination of bacteriolytic therapy with angiogenesis inhibitors targets two important components: the life line of a tumor and the hypoxic tumor tissue. While bacteria can 
destroy a tumor from its center, which is less accessible to other therapeutic agents, angiogenesis inhibitors can attack the tumor periphery by shutting down its blood supply, leaving the tumor minimal chances to survive. Furthermore, in contrast to other therapies, resistance to this combination approach is unlikely to develop [Zhou, 2005].

The paper'sresults also show that the used Salmonella strain induced a late apoptotic or necrotic stage. The tumor group (Gp II) and the VNP tumor bearing group (Gp V) revealed mild invasion of late stage apoptotic or necrotic cells, while the tumor bearing group treated with doxorubicin (VI) showed more necrotic or late stage apoptotic cells. Dominant late stage apoptotic or necrotic cells was observed on combining both treatments (Gp. VII). It seems likely that Salmonella infection induces host immune response including pro-inflammatory cytokines that induces apoptosis, the inhibition of VEGF production by the bacteria results in hypoxia of tissues that may die by apoptosis or necrosis (Sznol et al., 2000; Pawelek et al., 2003). This paperdata are consistent with Jia et al. (2005) who showed that the combination of $104 \mathrm{cfu}$ VNP20009 with $5 \mathrm{mg} / \mathrm{kg}$ of the chemotherapeutic agent rh-Endostatin induced more severe necrosis than either treatment, where Salmonella or rh-Endostatin alone displayed tissue necrosis between viable tumor cells (Jia et al., 2005). Several studies reported that VNP20009 induced apoptosis but they did not determine which stage of apoptosis [Jia et al., $2007 b]$. In the present study, necrosis or late stage apoptosis is observed. We suggest that the bacterial densities used have been probably higher than those that induce early apoptotic cell death or cells could have undergone apoptosis but not efficiently eliminated by macrophages and thus turn into secondary necrosis as described above.

Numerous downstream genes of p53 have been identified, including genes involved in growth arrest (such as p21CIP1 - the cyclin dependent kinase inhibitor), apoptosis (Bax pro-apoptotic protein), and auto-loop regulation of p53 [such as p53 inhibitor (mdm2 -mouse double minutes 2)] [Weinberg et al., 2007]. How p53 induces various signals and activates downstream genes in a timely and orderly manner is largely unknown. The results of the present study showed that the tumor cells of tumorbearing mice expressed extremely low levels of the p53 protein. This observation is consistent with the results obtained from similar studies, which indicated that p53 is commonly mutated in human tumors [Hollstein et al., 1991]. Loss of p53 function increases genomic instability and promotes tumor progression [Ko and Prives, 1996]. p53 knockout mice eventually develop a wide spectrum of tumors [Jacks et al., 1994]. In the present study the treatment with Salmonella VNP20009 brought about significantly higher amounts of the p53 protein as became evident from the immunohistochemical staining utilizing antip53 antibodies. This might be attributed to a host response to the non-genotoxic stress caused by the Salmonella infection. VNP uses a type three secretion system (TTSS), a needle system that injects bacterial pathogenic proteins into host cells [Patel $\boldsymbol{e t}$ al., 2005]. Avirulence factor for Salmonella (AvrA) is a Salmonella effector that becomes translocated into host cells [Hardt and Galan, 1997]. It has been previously shown that AvrA possesses acetyltransferase activity [Jones et al., 2008]. Although the exact function and mechanism of AvrA is not entirely clear, it is known that AvrA influences eukaryotic cell pathways that utilize ubiquitin [Ye et al., 2007] and acetylation [Jones et al., 2008]. Acetylation activates p53 and permits p53 to arrest cell cycle [Yamaguchi et al., 2009]. To our knowledge, this is the first to investigate the role of VNP20009 on p53 expression, it might be suggested that Salmonella VNP20009 infection activates the p53 pathway via AvrA acetyltransferase activity to increase the acetylation of p53, thereby inducing cell cycle arrest. Alternatively, the reported increase in ROS levels and the expected DNA damage might have caused the observed induction of 
p53 (Weinberg, 2007). Further, VNP20009 reduces the levels of VEGF as shown in this paper and in previous studies (Jia et al., 2005; Jia et al., 2007a]. Reduction in VEGF aggravates hypoxia, which induces the transcription of hypoxia inducible factor 1 (HIF-1) that, in turn, induces the transcription of p53 (Weinberg, 2007). Thus, results from the immunohistochemistry that showed late stage apoptotic cells in the VNP-treated groups could be induced via p53-dependent pathways.

Comparable high expression of p53 was also reported in tumor-bearing mice treated with Dox in conformity with the findings of Perego et al. (2001). This finding is attributed to activation, by phosphorylation, of JNK (a member of the mitogen-activated protein kinase family has been implicated in a wide array of physiological processes, including cell growth, differentiation and apoptosis) (Liu and Lin, 2005) and a subsequent stabilization of p53, which is prevented from binding to its inhibitory protein (MDM2) association (Buschmann $\boldsymbol{e t}$ al., 2000). Dox also activates.

Ceramide by de novo synthesis (El Btaour $\boldsymbol{e t}$ al., 2011), where Ceramide activates JNK. Moreover,

Doxorubicin generates ROS (Lentacker et al., 2010) which, in turn, activates JNK, and thus the stabilization and activation of p53 via JNK dependent pathways. Dox has also been suggested to activate the extracellular signal-regulated kinase (ERK), which in turn physically interacts with and phosphorylates p53 and thus activates it (Yeh $\boldsymbol{e t}$ al., 2004). Finally, it has been proven that DNA alkylators such as Dox activates PARP (Zong and Thompson, 2006) which, in turn, upregulates p53 (Whitacer et al., 1995). The enhanced expression seen in the present study could have resulted from the synergistic effect of both agents via the mechanisms described above.
Histopathological Examination: The aforementioned markers were further supported by the histopathological examination of the tumor tissue and liver of mice from the seven animal groups. The nonEAC mice, which were treated with VNP showed a diminishing pathological structure, to a great degree, towards normal intact histological feature of the liver. On the other hand, mice treated with Dox showed degeneration of hepatocytes with karyolysis and pyknosis of their nuclei. Dilated central vein with heamorage, dilated blood sinusoids and monocytes infiltration were also observed. Untreated EAC-bearing mice showed large masses of tumor cells, pressing and shifting on the muscle tissue. The same mice group, which received 104 bacterial showed less condensation of tumor cells and regeneration of the striated muscle with healthy nuclei. On the other hand, EACbearing mice treated with Dox showed relatively dense tumor cells pressing on the muscle tissue. Rupture of the muscular tissue was also seen (Figure 8). Liver sections of mice bearing EAC and treated with bacteria showed partial protection and regeneration of hepatocytes as compared to the untreated group where mostly normal hepatocytes with normal nucleus, narrow blood sinusoids and normal central vein are seen. On the other hand, liver sections of mice bearing EAC and treated with doxorubicin showed infiltration of monocytes around the dilated central vein, dilated sinusoids and pyknotic cells. Liver sections of mice receiving both treatments showed relatively normal hepatocytes and dilatation of sinusoids. Infiltration of monocytes around the central vein is also seen. These results suggest that treatement with bacteria alone showed significant decrease in the tumor mass with relatively no side effects on the liver. These findings are further supported by Pawelek et al. (1997) who stated that bacteria can selectively grow in transplanted tumors in mice, preferentially replicate in tumor tissue, achieve tumor to normal tissue ratios in excess of 1,000 to 1 and result in reduced tumor growth. 
In conclusion, using a murine EAC model, The authors provesthat monotherapy with $2 \times 105$ cells of VNP results in significant regression in tumor volume, normal levels of liver (ALT, AST) and kidney (urea) function tests, significantly lower free radical generation by host animals, reduction in VEGF levels, and enhanced expression of the tumor suppressor p53. Although comparable antitumor effects were obtained with a low dose of Dox (5 mg/g), VNP seems to obviate the reported toxicity of the latter agent. Thus, immunotherapy via salmonella could open the horizon to cancer therapy and hold big hopes to patients to be treated with a more economic and less painful strategy. Further studies should be carried out in this field to illuminate the exact antitumor mechanisms of Salmonella and its application on human.

\section{Acknowledgments:}

The authors are grateful to Prof. Brooks Law (Yale University, USA) for providing the Salmonella strain VNP20009 as a generous gift. They also thank Prof. Zahira Tawfik (National center for radiation research and technology) for her kind assistance. Special thanks to Prof. Seham Abouel Nour (National center for radiation research and technology) for critically reading the histology sections.

\section{References:}

Armitage, P. \& Berry, G. (1987). In: Statistical Methods in Medical Research, Armitage, P. and Berry, G. (Eds.). pp. 186-00, Oxford: Blackwell Scientific Publications.

Avogadri, F., Mittal, D., Saccheri, F., Sarrafiore, M., Ciocca, M., Larghi, P., Orecchia, R. \& Rescigno, M. (2008). "Intra-Tumoral Salmonella Typhimurium Induces a Systemic Anti-Tumor Immune Response That is Directed by Low-Dose Radiation to Treat Distal Disease," Eur. J. Immunol, 38(7) 1937 47.
Banchroft, J. D. \& Stevens, A. (1996). "Theory and Practice of Histological Techniques," Fourth Ed. Churchil Livingstone, New York, London, San Francisco, Tokyo.

Brown, J. M. \& Giaccia, A. J. (1998). "The Unique Physiology of Solid Tumors: Opportunities (And Problems) for Cancer Therapy," Cancer Res. 58, 1408-16.

Buschmann, T., Adler, V., Matusevich, E., Fuchs, S. Y. \& Ronai, Z. (2000). "P53 Phosphorylation and Association with Murine Double Minute 2, C-Jun NH2Terminal Kinase, P14arf and P300/CBP during the Cell Cycle and After Exposure to Ultraviolet Irradiation," Cancer Res., 60, 896900.

Cao, R., Farnebo, J., Kurimoto, M. \& Cao, Y. (2007). 'Interleukin-18 Acts as an Angiogenesis and Tumor Suppressor,' FASEB. J, 13(15) 2195-202

Clairmont, C., Lee, K. C., Pike, J., Ittensohn, M., Low, K. B., Pawelek, J., Bermudes, D., Brecher, S. M., Margitich, D., Turnier, J., Li, Z. \& Luo, X. (2000). "Biodistribution and Genetic Stability of the Novel Antitumor Agent VNP20009, A Genetically Modified Strain of Salmonella Typhimurium," J. Infect. Dis, 181, 1996-2002.

Dang, L. H., Bettegowda, C., Huso, D. L., Kinzler, K. W. \& Vogelstein, B. (2001). "Combination Bacteriolytic Therapy for the Treatment of Experimental Tumors", Proc. Natl. Acad. Sci. USA, 98, 15155-15160.

Duyndam, M. C., Van Berkel, M. P., Dorsman, J. C., Rockx, D. A., Pinedo, H. M. \& Boven, E. (2007). "Cisplatin and Doxorubicin Repress Vascular Endothelial Growth Factor Expression and Differentially Down-Regulate Hypoxia-Inducible Factor I Activity in Human Ovarian Cancer Cells," Biochem. Pharmacol, 74(2) 191-201. 
Elias, J. M., Gown, A. M., Nakamura, R. M., Wilbur, D. C., Herman, G. E., Jaffe, E. S., Battifora, H. \& Brigati, D. J. (1989). Am. J. Clin. Pathol., 92, 836-843.

Fahim, F. A., Esmat, A. Y., Mady, E. A. \& Amin, M. A. (1997). "Serum LDH and ALP Isozyme Activities in Mice Bearing Solid Ehrlich Carcinoma and/or Treated with Maximum Tolerated Dose (MTD) of Aloin," Disease Markers,13, 183-193.

Fornari, F. A., Randolph, J. K., Yalowich, J. C., Ritke, M. K. \& Gewirtz, D. A. (1994). "Interference by Doxorubicin with DNA Unwinding in MCF-7 Breast Tumor Cells," Mol. Pharmacol, 45, 649-56.

Ghosh, S., Roy, S., Banerjee, M. \& Maity, P. (2004). "Modulation of Tumor Induced Angiogenesis in EAT," J. Exp. Clin. Cancer Res, 23(4) 681-90.

Gohn, A. (1986). 'ESR and Elementary Particle Applications,' John Wiley, New York.

Gothoskar, S. V. \& Ranadive, K. J. (1971). "Anticancer Screening of SAN-AB: An Extract of Marking Nut Semecarpus Anacardium," Indian. J. Exp. Biol, 9, 372-5.

Hardt, W. D. \& Galán, J. E. (1997). "A Secreted Salmonella Protein with Homology to an Avirulence Determinant of Plant Pathogenic Bacteria," Proc. Natl. Acad. Sci. U S A. 94(18):9887-92.

Hassan, A. I. \& Abdel-Gawad, E. I. (2010). "Effect of Zizyphus Leaves Extract on Mice Suffering from Ehrlich Ascites Carcinoma," Nature and Science, 8(11) 234-244.

Heckly, R. J. (1972). "Chapter 5" Free Radicals in Dry Tissues, In Swartz H. M., Bolton, J. R. \& Borg, D.C. (Eds.) Biological Applications of Electron Spin Resonance. Wiley-Interscience, a Division of John Wiley and Sons, Inc. New York, London, Sydney, Toronto.
Heckly, R. J. (1976). "Chapter 4" Free Radicals in Dry Biological Systems, In Pryor W. A. (Ed.) Free Radicals in Biology," Volume II. Academic Press. New York, San Francisco, London. A Subsidiary of Harcourt Brace. Jovanovich, Publishers.

Hollstein, M., Sidransky, D., Vogelstein, B. \& Harris, C. C. (1991). "P53 Mutations in Human Cancers," Science, 253, 49-53.

Jacks, T., Remington, L, Williams, B. O., Schmitt, E. M., Halachmi, S., Bronson, R. T. \& Weinberg R. A. (1994). "Tumor Spectrum Analysis in P53-Mutant Mice," Curr. Biol., 4, 1-7.

Jain, R. K. (2001). "Delivery of Molecular and Cellular Medicine to Solid Tumors," Adv. Drug Deliv. Rev, 46, 149-68.

Jia, L. J., Wei, D. P., Sun, Q. M., Huang, Y., Wu, Q. \& Hua Z. C. (2007a). "Oral Delivery of Tumor-Targeting Salmonella for Cancer Therapy in Murine Tumor Models," Cancer Sci, 98(7) 1107-12.

Jia, L. J., Wei, D. P., Sun, Q. M., Jin, G. H., Li, S. F., Huang, Y. \& Hua, Z. C. (2007b). "TumorTargeting Salmonella Typhimurium Improves Cyclophosphamide Chemotherapy at Maximum Tolerated Dose and Low-Dose Metronomic Regimens in a Murine Melanoma Model," Int. J. Cancer, 121(3) 666-74.

Jia, L.- J., Xu, H.- M., Ma. D.- Y., Hu, Q.- G., Huang, X.- F., Jiang, W.- H., Li, S.- F., Jia, K.- Z., Huang, Q.- L. \& Hua, Z.- C. (2005). "Enhanced Therapeutic Effect by Combination of TumorTargeting Salmonella and Endostatin in Murine Melanoma Model," Cancer Biol. Ther, 4, 840-5.

Jing, L. I. U. \& Anning, L. I. N. (2005). "Role of JNK Activation in Apoptosis: A Double-Edged Sword," Cell Res., 15, 36-42. 
Jones, R. M., Wu, H., Wentworth, C., Luo, L., Collier-Hyams, L. \& Neish, A. S. (2008). "Salmonella Avra Coordinates Suppression of Host Immune and Apoptotic Defenses via JNK Pathway Blockade," Cell Host Microbe, 3(4) 233-44.

Ko, L. J. \& Prives, C. (1996). "P53: Puzzle and Paradigm," Genes Dev., 10, 1054-1072.

Lee, C. H., Wu, C. L., Tai, Y. S. \& Shiau, A. L. (2005). "Systemic Administration of Attenuated Salmonella Choleraesuis in Combination with Cisplatin for Cancer Therapy," Mol. Ther,11(5) 707-16.

Lentacker, I., Geers, B., Demeester, J., De Smedt, S. C. \& Sanders, N. N. (2010). "Design and Evaluation of Doxorubicin-Containing Microbubbles for Ultrasound-Triggered Doxorubicin Delivery: Cytotoxicity and Mechanisms Involved," Mol. Ther, 18(1) 1018.

Low, K. B., Ittensohn, M., Luo, X., Zheng, L. M., King, I., Pawelek, J. M. \& Bermudes, D. (2004) "Construction of VNP20009: A Novel, Genetically Stable Antibiotic-Sensitive Strain of Tumor-Targeting Salmonella for Parenteral Administration in Humans," Methods Mol. Med, 90, 47-60.

Maeda, H. \& Akaike, T. (1998). "Nitric Oxide and Oxygen Radicals in Infection, Inflammation, and Cancer," Biochemistry (Mosc),63(7) 854-65.

McMahon, G. (2000). "VEGF Receptor Signaling in Tumor Angiogenesis," Oncologist, 5, 3-10.

Morjani, H., Greffe, Y., Charpentier, E. \& Martiny, L. (2011). "Role of JNK/ATF-2 Pathway in Inhibition of Thrombospondin-1 (TSP-1) Expression and Apoptosis Mediated by Doxorubicin and Camptothecin in FTC133 Cells," Biochim Biophys Acta.,1813(5) 695-703.
NIH Publication, (1985). Animals in Research, Health Research Extension Act Of 1985. Public Law, 99-158.

Patel, J. C., Rossanese, O. W. \& Galán J. E. (2005). "The Functional Interface between Salmonella and Its Host Cell: Opportunities for Therapeutic Intervention," Trends Pharmacol. Sci., 26(11) 564-70.

Patyar, S., Joshi, R., Byrav, D. S. P., Prakash, A., Medhi, B. \& Das, B. K. (2010). "Bacteria in Cancer Therapy: A Novel Experimental Strategy," J. Biomed. Sci, 17(1) 21-30.

Pawelek, J. M., Low, K. B. \& Bermudes, D. (1997). "Tumor-Targeted Salmonella as a Novel Anticancer Vector," Cancer Res, 57, 4537-4544.

Pawelek, J. M., Low, K. B. \& Bermudes, D. (2003). "Bacteria as Tumor-Targeting Vectors," Lancet. Oncol, 4, 548-556.

Perego, P., Corna, E., De Cesare, M., Gatti, L., Polizzi, D., Pratesi, G., Supino, R. \& Zunino, F. (2001). "Role of Apoptosis and ApoptosisRelated Genes in Cellular Response and Antitumor Efficacy of Anthracyclines," Curr. Med. Chem. 8: 31-37.

Ribble, D., Goldstein, N. B., Norris, D. A. \& Shellman, Y. G. (2005). "A Simple Technique for Quantifying Apoptosis in 96-Well Plates," BMC. Biotechnol, 10, 5-12.

Rosenberg, S. A., Spiess, P. J. \& Kleiner, D. E. (2002). "Antitumor Effects in Mice of the Intravenous Injection of Attenuated Salmonella Typhimurium," J. Immunother. 25(3) 218-25.

Sakr, Mahran, H. A. \& Lamfon, H. A. (2011). "Protective Effect of Ginger (Zingiber Officinale) on Adriamycin - Induced Hepatotoxicity in Albino Rats," J. Med. Plant. Res. 5(1): 133-140.

Sannino, P. \& Shousha, S. (1994). "Demonstration of Oestrogen Receptors in Paraffin Wax Sections of Breast Carcinoma 
Using the Monoclonal Antibody 1D5 and Microwave Oven Processing," J. G. Clin. Pathol, 47, 90-92.

Sheela, M., Lingaraju, Kaveri Keshavaiah \& Bharathi, P. Salimath (2008). "Inhibition of in Vivo Angiogenesis by Anacardium Occidentale Involves Repression of the Cytokine VEGF Gene Expression," Dug Disc. Ther, 2(4) 234-244.

Shinde, N., Jagtap, A. Undale, V., Kakade, S., Kotwal, S. \& Patil, R. (2010). 'Protective Effect of Lepidium Sativum against DoxorubicinInduced Nephrotoxicity in Rats,' J. Pharmaceut, Biol. and Chem. Sci. 1 (3) 42-49.

Sznol, M., Lin, S. L., Bermudes, D., Zheng, L. \& King, I. (2000). "Use of Preferentially Replicating Bacteria for the Treatment of Cancer," J. Clin. Invest, 105, 1027-30.

Veikkola, T. T. \& Alitalo, K. (2004). 'VEGF's, Receptors and Angiogenesis,' Semin. Cancer Biol, 9, 211-220.

Vincent, P. C. \& Nicholls, A. (1967). "Comparison of the Growth of the Ehrlich Ascites Tumor in Male and Female Mice," Cancer Res, 27(1) 1058-1065.

Wallace, K. B. (2007). "Adriamycin-Induced Interference with Cardiac Mitochondrial Calcium Homeostasis," Cardiovasc. Toxicol. 7:101-107.

Weinberg, J. M., Davis, J. A., Abarzua, M., Kiani, T. \& Kunkel, R. (1990). "Protection by Glycine of Proximal Tubules from Injury Due to Inhibitors of Mitochondrial ATP Production," Am. J, 258,1127-1140.

Weinberg, R. A. (2007). The Biology of Cancer, PP.796. Garland Science. Taylor and Francis Group, LLC.

Whitacre, C. M., Hashimoto, H., Tsai, M. L., Chatterjee, S., Berger, S. J., Berger, N. A. (1995). "Involvement of NAD-Poly (ADPRibose) Metabolism in P53 Regulation and Its
Consequences," Cancer Res. 55(17) 3697701.

Wu, S., Ye, Z., Liu, X., Zhao, Y., Xia, Y., Steiner, A., Petrof, E. O., Claud, E. C. \& Sun, J. (2010). "Salmonella Typhimurium Infection Increases P53 Acetylation in Intestinal Epithelial Cells," Am. J. Physiol. Gastrointest. Liver Physiol., 298(5) 784-94.

Yamaguchi, H., Woods, N. T., Piluso, L. G., Lee, H. H., Chen, J., Bhalla, K. N., Monteiro, A., Liu, X., Hung, M. C. \& Wang, H. G. (2009). "P53 Acetylation Is Crucial for Its TranscriptionIndependent Proapoptotic Functions," J. Biol. Chem., 284(17) 11171-83.

Yazawa, K., Fujimori, M., Amano, J., Kano, Y. \& Taniguchi, S. (2000). "Bifidobacterium Longum as a Delivery System for Cancer Gene Therapy: Selective Localization and Growth in Hypoxic Tumors," Cancer Gene Ther, 7, 269-274.

Ye, Z., Petrof, E. O., Boone, D., Claud, E. C. \& Sun, J. (2007). "Salmonella Effector Avra Regulation of Colonic Epithelial Cell Inflammation by Deubiquitination," Am. J. Pathol., 171(3) 882-92.

Yeh, P. Y., Chuang, S. E., Yeh, K. H., Song, Y. C., Chang, L. L. \& Cheng, A. L. (2004). "Phosphorylation of P53 on Thr55 by ERK2 Is Necessary for Doxorubicin-Induced P53 Activation and Cell Death," Oncogene, 23(20) 3580-8.

Yu, Y. A., Shabahang, S., Timiryasova, T. M., Zhang, Q., Beltz, R., Gentschev, I., Goebel, W. \& Szalay, A. A. (2004). "Visualization of Tumors and Metastases in Live Animals with Bacteria and Vaccinia Virus Encoding Light-Emitting Proteins," Nat. Biotechnol, 22, 313-320.

Zhou, S. (2005). "Combination Therapy with Bacteria and Angiogenesis Inhibitors: Strangling Cancer without Mercy," Cancer. Biol. Ther. 4(8) 846-7.

Zong, W. X. \& Thompson, C. B. (2006). "Necrotic Death as A Cell Fate," Genes Dev. 20(1) 1-15. 